\title{
Comparative studies on mechanical properties of WC-Co composites sintered by SPS and conventional techniques
}

\author{
Yuri Pristinskiy ${ }^{l,}{ }^{*}$, Nikita Peretyagin ${ }^{l}$, and Nestor Washington Solis Pinargote ${ }^{l}$ \\ ${ }^{1}$ Moscow State University of Technology “STANKIN”, Vadkovskij per. 1, Moscow, 101472, Russian Federation
}

\begin{abstract}
Spark plasma sintering (SPS) is an extremely fast solidification technique for compounds that are difficult to sinter within the material group metals, ceramics, or composites thereof, SPS uses a uniaxial pressure and a very rapid heating cycle to consolidate these materials. With SPS the main benefit is the ability to control the WC grain size due to the short sintering times at high temperature. Additionally, its allows to avoid negative reactions between $\mathrm{WC}$ and cobalt and to minimize the formation of undesirable phases in sintered composites. The WC-6wt.\% Co cermet prepared by SPS processing achieves the enhanced mechanical properties with the hardness of $18.3 \mathrm{GPa}$ and the fracture toughness of $15.5 \mathrm{MPa} \cdot \mathrm{m}^{1 / 2}$ in comparison to standard reference tungsten carbide/cobalt material.
\end{abstract}

\section{Introduction}

Today, the tungsten carbide (WC) and cobalt (Co) alloy is a widely spread material for tool making [1]. It is used extensively in machining, mining, and making drilling tools $[2,3]$. Thanks to the presence of cemented carbides, such tools are harder and more heat-resistant. However, they are less strong and are prone to brittle fractures [4]. Increasing the amount of WC fraction and decreasing the growth of its grain during sintering can considerably improve the hardness and toughness; at the same time, in order to increase fracture resistance, the content of cobalt have to be increased $[5,6]$. Thanks to their good hardness and fracture toughness balance, carbides with 5 to $10 \mathrm{wt}$ \% Co are the most promising materials for making cutting inserts [6]. To improve mechanical characteristics and performance of carbide tools, new processing methods of sintering should be used.

As of today, carbide cutting inserts are conventionally made by such methods as hot pressing [7] and hot isostatic pressing [8]. However, these methods have a number of drawbacks like low sintering rate, high equipment costs, low reproducibility of the output, etc. From this perspective, spark plasma sintering seems a very promising method $[9,10]$.

Spark plasma sintering (SPS) or pulsed electric current sintering (PECS) is a sintering technique utilizing uniaxial force and a pulsed (on-off) direct electrical current (DC) under low atmospheric pressure to perform high speed consolidation of the powder. This direct way of heating allows the application of very high heating and cooling rates, enhancing densification over grain growth promoting diffusion mechanisms allowing maintaining the intrinsic properties of nanopowders in their fully dense products $[11,12]$. The heating rate during the SPS process depends on the geometry of the container/sample ensemble, its thermal and electrical properties, and on the electric power supplier. Heating rates as high as $1000{ }^{\circ} \mathrm{C} / \mathrm{min}$ can be achieved. As a consequence, the processing time typically takes some minutes depending on the material, dimensions of the piece, configuration, and equipment capacity [13].

In addition, high pressure and heating rate allow decreasing sintering temperature lower than eutectic temperature $\left(\approx 1320^{\circ} \mathrm{C}\right)$ for WC-6wt.\% Co system. Therefore, it permits to avoid the appearance of $\eta$-phase and prevents the growth of $\mathrm{WC}$ grains.

The purpose of the present study was to investigate the dependence of the basic SPS processing parameters, such as temperature, pressure, and time on the mechanical properties of WC-6wt.\% Co composites.

\section{Materials and characterization}

\subsection{Raw materials}

Commercially available submicron powder WC-6 wt.\% Co (Plasmotherm, Moscow, Russia). with an average tungsten carbide particles size of $1.5 \mu \mathrm{m}$ and average cobalt particle is $40 \mathrm{~nm}$ was used as an initial material.

\subsection{Powder processing and sintering}

Powder densification was performed by SPS KCE-FCTH-HP-D25-SD (FCT Systeme GmbH, Rauenstein, Germany) at a maximum temperature of $1000-1500^{\circ} \mathrm{C}$ (increments of $50^{\circ} \mathrm{C}$ ), reached under vacuum at a heating rate of $100^{\circ} \mathrm{C} / \mathrm{min}$, and an applied pressure of $30 \mathrm{MPa}$. The final temperature and pressure were maintained for 5 $\mathrm{min}$. The sintered specimens had diameters of $20 \mathrm{~mm}$ and thicknesses of $5 \mathrm{~mm}$. Taking into account that these parameters were chosen to study only the effect of

\footnotetext{
${ }^{*}$ Corresponding author: y.pristinskiy@gmail.com
} 
sintering temperature on the mechanical properties of the samples.

It is known that applied pressure and dwelling time affect the mechanical properties of samples as well [14]. Therefore, for subsequent studies dwelling time were increased up to $10 \mathrm{~min}$ and pressure was varied in the range from 30 to $80 \mathrm{MPa}$.

The commercially available WC-6wt.\% Co cermet fabricated by hot press sintering at $1400^{\circ} \mathrm{C}$ was used as the reference material.

\subsection{XRD characterization}

XRD analyses (Empyrean diffractometer, PANalytical, Almelo, Netherlands, $\mathrm{Cu}-\mathrm{K} \alpha$ radiation, wavelength $1.5405981 \AA$, accelerating voltage $60 \mathrm{kV}$, beam current 30 $\mathrm{mA}$ ) of the raw powder as well as of the sintered samples were conducted in a step scanning mode at diffraction angles $2 \theta$ ranging from $25^{\circ}$ to $100^{\circ}$ (step size $0.05^{\circ}$ ).

\subsection{Microstructural and mechanical characterization}

The true density of the raw powder was measured using a helium pycnometer AccuPyc II 1340 (Micromeritics, Norcross, USA). The device operation principle involves sample placing into a calibrated chamber filled with helium. To clean the sample surface from water vapors and impurities, one need to start from several helium blowdowns, and after that the analysis itself can be conducted. The gas molecules penetrate the tiniest sample pores. In other words, the sample pushes out the gas volume equal to the volume of the true solid phase only. In case the sample weight was preliminary entered, the device will calculate its density.

Scanning electron microscopy characterization was carried out on polished down to $1 \mu \mathrm{m}$ surfaces by VEGA 3 LMH (SEM Tescan, Brno, Czech Republic).

The density of the sintered samples $(\rho)$ was measured in distilled water using Archimedes' principle and was compared with the theoretical value, calculated according to the rule of mixtures.

In order to quantify the WC average grain size, the sintered and polished samples were thermally etched in vacuum for $20 \mathrm{~min}$ at a temperature of $1200^{\circ} \mathrm{C}$, and the linear intercept method (LIM) was used [15].

Vickers hardness, $H v$, was measured on polished surfaces using a Vickers diamond indenter (QNess A10 Microhardness Tester, Salzburg, Austria), applying a load of $1 \mathrm{~kg}$ and an indentation time of $10 \mathrm{~s}$. The hardness results were averaged over 10 indentations per specimen.

Fracture toughness $\left(K_{l c}\right)$ was determined from Vickers indentations obtained with a load of $10 \mathrm{~kg}$ for 10 seconds. The sizes of the corresponding indentations and crack lengths were measured using SEM. The $H V$ and $K_{l c}$ of refence materials were measured using the same equipment and under the same testing conditions. The method and formulas for calculating $H v$ and $K_{l c}$ have been reported elsewhere [16].

\section{Results and discussion}

\subsection{XRD analyses}

$\mathrm{X}$-ray diffraction was carried out for the starting powder and for the sintered sample $\left(1300^{\circ} \mathrm{C} / 10 \mathrm{~min} / 80 \mathrm{MPa}\right)$ (Fig.1). XRD analysis revealed the presence of tungsten carbide $(\boldsymbol{\square})$ and cobalt $(\diamond)$ phases, without any additional peaks appearing.

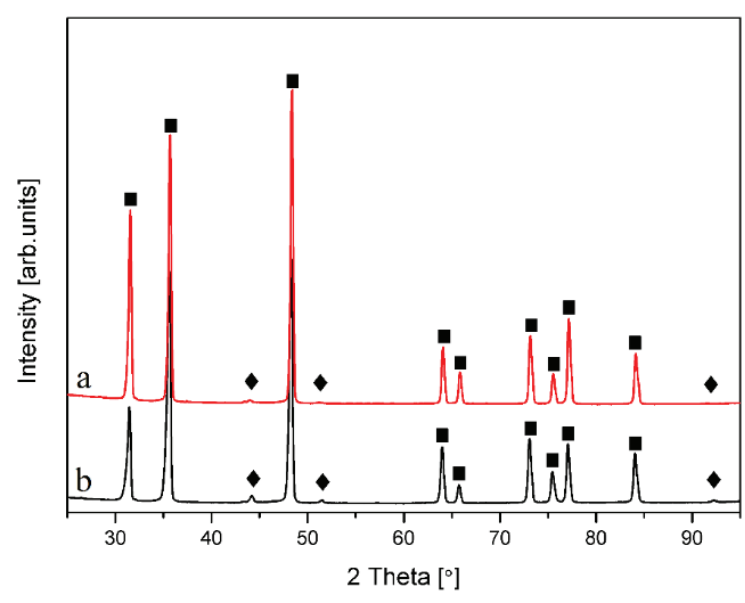

Fig. 1. XRD patterns of raw powder (a) and SPS sintered $\left(1300^{\circ} \mathrm{C} / 10 \mathrm{~min} / 80 \mathrm{MPa}\right)$ sample (b).

\subsection{Microstructure characterization}

Typical thermally etched microstructure of the SPS sintered WC- $6 \%$ Co cermet is shown in Fig. 2. The grains have fairly equiaxed shapes. No residual porosity could be detected in microstructure. The average grain size of WC was about $0.7 \pm 0.5 \mu \mathrm{m}$.

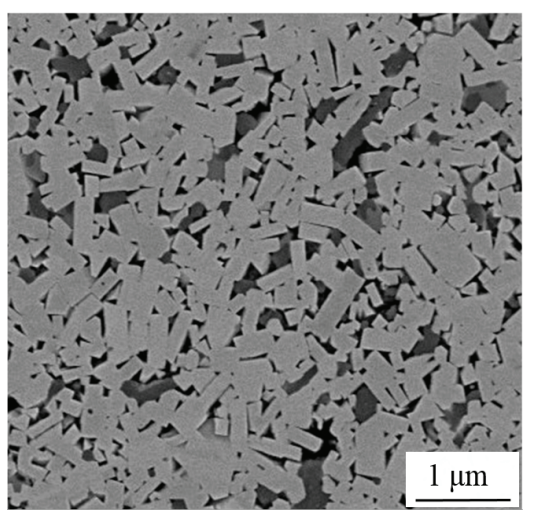

Fig. 2. SEM images of polished and thermally etched sections of SPS sintered $\left(1300^{\circ} \mathrm{C} / 10 \mathrm{~min} / 80 \mathrm{MPa}\right) \mathrm{WC}-6 \%$ Co cermet. Light grey phase is carbide particles.

\subsection{Mechanical properties}

The influence of sintering temperature on density, hardness and fracture toughness of sintered composites presented on Fig.3. All samples sintered at $1300^{\circ} \mathrm{C}$ and higher temperature were reached the maximum densification (99.0-99.5\% th.). High sintering temperature leads to an increase in relative density and decrease in porosities due to the formation of a liquid phase during sintering. 
Samples sintered at $1300{ }^{\circ} \mathrm{C}$ showed the fracture toughness of $10 \pm 0.4 \mathrm{MPa} \cdot \mathrm{m}^{1 / 2}$, and hardness of $17.3 \pm$ $0.8 \mathrm{GPa}$, that higher than values obtained for the reference material.

However, it is worth mentioning that further increases in temperature do not result in significant changes in hardness while fracture toughness becomes considerably lower (Fig. 3). It is explained by the fact that at temperature higher that eutectic intermediate phases $\left(\mathrm{Co}_{3} \mathrm{~W}_{3} \mathrm{C}, \mathrm{W}_{2} \mathrm{C}\right.$ or $\left.\mathrm{WO}_{3}\right)$ can occur and play a negative role in fracture toughness.

Nevertheless, it needs to be noticed, that the mechanical performance of the test specimens was studied only dependent on the differentiating sintering temperatures, at the constant sintering pressure and dwelling time.

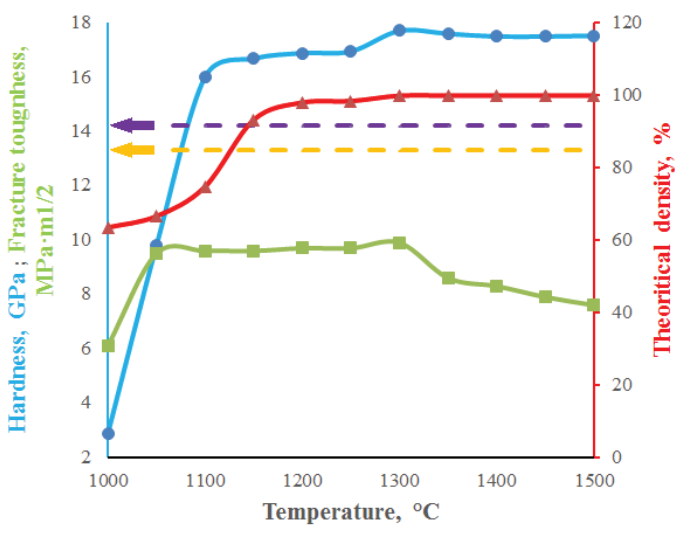

Fig. 3. Influence of SPS temperature on hardness ( - ), density $(-)$, and fracture toughness $(-)$ of sintered cermet. Fracture toughness (---) and hardness (---) of reference material is presented as well.

In order to investigate the effect of consolidation pressure and dwelling time on the mechanical properties of the cermet at the optimal temperature, dwelling time were increased up to $10 \mathrm{~min}$ and pressure was varied in the range from 30 to $80 \mathrm{MPa}$. Fig. 4 shows the effect of applied pressure on the $H V$ and $K_{I c}$ of $\mathrm{WC}-6 \%$ Co composites.

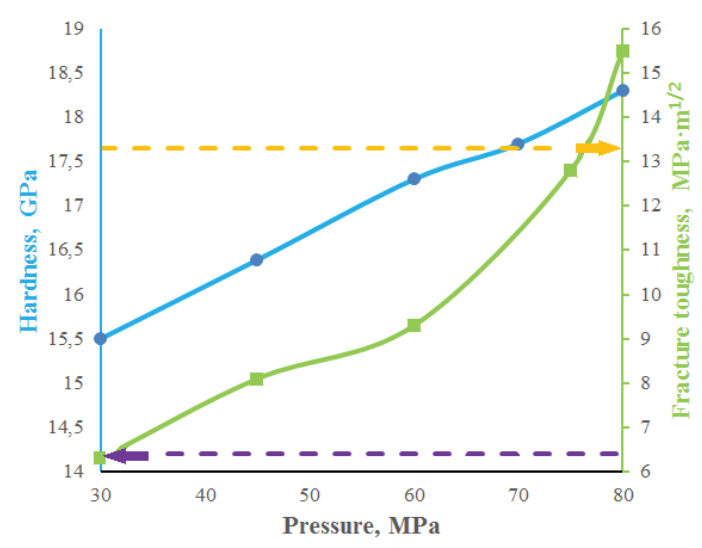

Fig. 4. Evolution of hardness (- and fracture toughness (-) of WC- $6 \%$ Co composites sintered at $1300^{\circ} \mathrm{C}$ with dwelling time 10 minutes under differentiating pressures. Fracture toughness (---) and hardness (---) of reference material is presented as well.
This data shows that the mechanical behavior of these composites improves with higher pressure / dwelling time and reaching a maximum hardness of $18.3 \pm 0.6 \mathrm{GPa}$ and a maximum fracture toughness of $15.5 \pm 0.3 \mathrm{MPa} \cdot \mathrm{m}^{1 / 2}$ at $80 \mathrm{MPa}$.

This could be explained by the fact when pressure is applied to the compacted powder, it is transferred through the contacts between the particles and with increasing consolidation processes, both the area and the number of contacts between the powder particles increase. The pressure is manifested in "mechanical" effects, leading to the mixing of particles, the destruction of agglomerates, etc. In addition, the pressure enhances the driving force associated with the surface tension, which in turn leads to the effects of flow and creep, increases diffusion from the grain boundaries. Thus, the applying of pressure during sintering makes it possible to achieve high density at the same temperatures and, accordingly, improve the mechanical properties of the sintered material.

Fig. 5 shows the Vickers indentation cracks induced on the surfaces of sintered sample. The crack path goes along the cobalt binder rather than tungsten carbide grains and not propagate rapidly due to cobalt plasticity. Thus, homogeneous distribution of metal binder in SPSed cermet is crucial not only for better WC grain contiguity, but also can prevent brittle fracture and cracks propagation and, consequently, increase fracture toughness.

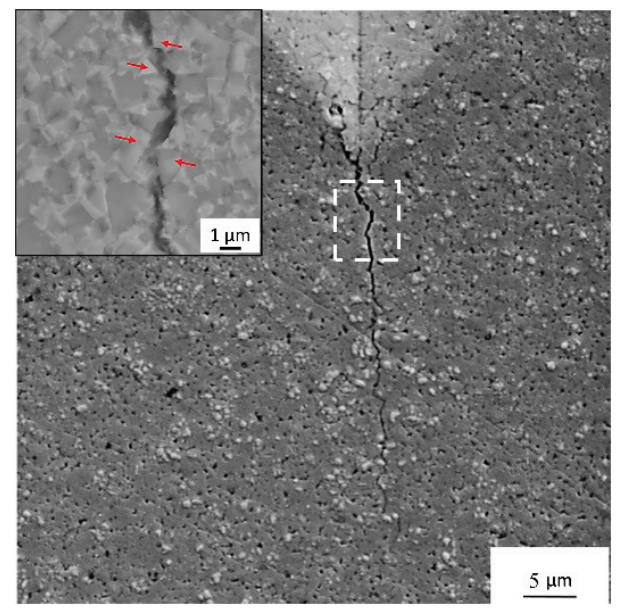

Fig.5. Vickers indentation cracks induced on the surfaces of SPSed cermet. Dashed area denotes where close-up (left upper corner) was taken.

In addition, these high mechanical values have been confirmed from the XRD data, that not identify any additional $\eta$ - and $\theta$ - phases that could have negative effects on the mechanical properties (Fig. 1b).

\section{Conclusion}

WC-6\% Co cermets have been successfully fabricated by Spark Plasma Sintering. Results showed that all free basic sintering parameters (temperature, pressure, time) have a significant effect on the mechanical performance of sintered materials. High pressure $(80 \mathrm{MPa})$ can decrease down to $1300^{\circ} \mathrm{C}$ sintering temperature and 
simultaneously enhance fracture toughness (15.5 $\left.\mathrm{MPa} \cdot \mathrm{m}^{1 / 2}\right)$ and hardness $(18.3 \mathrm{GPa})$. Compared to the refence material, the SPSed WC- $6 \%$ Co samples in a percentage ratio increased the rate of fracture toughness and hardness by $17 \%$ and $29 \%$, respectively. The results presented in this study are promising, but further work is needed to optimize the sintering process to produce the material of superior characteristics.

Authors would like to thank The Ministry of Education of the Russian Federation supported this work by contract No. 14.577.21.0199, a unique identifier of contract RFMEFI57715X0199.

\section{References}

1. P. Siwak, D. Garbiec, Trans. Nonferrous Met. Soc. China 26, 2641 (2016)

2. G.-Q. Shao, X.-L. Duan, J.-R. Xie, et al., Rev. Adv. Mater. Sci. 5 (4), 281 (2003)

3. E. Lassner, W.-D. Schubert, Kluwer Academic Publishers (Plenum Press, London, 2000).

4. M. Eriksson, M. Radwan, Z. Shen, Int. J. Refrac. Met. Hard Mater. 36, 31 (2013)

5. K. Hwan-cheol, S. In-jin, Y. Jin-kook, D. Jung-mann, Int. J. Refrac. Met. Hard Mater. 25, 46 (2007)

6. S. Wei, S. Ye-Xi, Y. Hai-Lin, Z. Xian-Qi, R. JianMing, Construction and Building Materials, 91, 133 (2015)

7. C.-Chang, S. Lan, Tang Hua, Q. Xuan-Hui. Int. J. Refrac. Met. Hard Mater, 25, 53 (2007)

8. W. Chong-Bin, S. Xiao-Yan, Z. Shi-Xian, Z. Li, Liu Wen-Bin, Int. J. Refrac. Met. Hard Mater. 28, 567 (2010)

9. C.F. Gutiérrez-González, M. Suarez, S. Pozhidaev, S. Rivera, P. Peretyagin, W. Solís, L.A. Díaz, A. Fernandez , R. Torrecillas, J. Eur. Ceram. Soc. 36, 2149 (2016)

10. S. S. Pozhidaev, A. E. Seleznev, N. W. Solis Pinargote and P. Yu. Peretyagin, Mechanics \& Industry 16, 710 (2015)

11. C. F. Gutierrez-Gonzalez, N. W. Solis Pinargote, S. Agouram, P. Y. Peretyagin, S. Lopez-Esteban and R. Torrecillas, Mechanics \& Industry 16, 703 (2015)

12. N. W. Solís, P. Peretyagin, R. Torrecillas, A. Fernández, J. L. Menéndez, C. Mallada, L. A. Díaz, J. S. Moya, Electroceram, 38,119 (2017)

13. D. I. Yushin, V. Smirnov, N. Solis Pinargote, P. Yu. Peretyagin, V. A. Kuznetsov and R. Torrecillas, Rus. Ing. Res. 36, 410 (2016)

14. R. Rumman , Z. Xie , S.-J. Hong, R. Ghomashchi, Materials and Design, 68, 221 (2015)

15. J.C. Wurst, J.A. Nelson, Ceram. Soc. 55(2), 109 (1972)

16. A. Smirnov, H. D. Kurland, J. Grabow, F. A. Müller, J. F. Bartolomé, J. Eur. Ceram. So. 35, 2685 (2015) 